\title{
Living with hearing loss: psychosocial impact and the role of social support
}

\begin{abstract}
Background: Hearing loss is one of the most common diseases affecting older occupying the $10^{\text {th }}$ place among the diseases with greatest influence in human life conditions, and in Portugal it is considered the 5 th main cause of suffering in this population.

Objectives: The present study was designed to evaluate the psychosocial impact (daily activities, social activities, general emotional state) of this disease as a function of the hearing loss degree (mild, moderate or severe)On the other hand, considering the protector role that social support (instrumental and informational) can play in chronic diseases, we analyzed the moderation role of variable in the relation between hearing loss and negative emotional symptoms (anxiety, depression and stress).
\end{abstract}

Methods: One hundred and ten patients with a hearing loss diagnosed, with a mean age of 70 years old $(\mathrm{SD}=7.89)$ participated in the study. Self report measures of social support and emotional distress were administered and socio-demographic characteristics were collected.

Results: In general, the results showed that hearing loss has a negative role in daily and social activities as well as in the general emotional state of these patients. Nevertheless, for negative emotional states such as anxiety, depression and stress, the instrumental support had a buffering effect, since independently from the hearing loss degree, higher social support was associated with lower levels of anxiety, depression and stress.

Conclusions: Overall, the results contribute to enhance the protective role that social support might have in chronic diseases and particularly in hearing loss.

Keywords: aging, hearing loss, social support, anxiety, depression, stress
Volume 2 Issue 5 - 2015

\author{
Sara MVeiga,' Joana D Alexandre, ${ }^{2}$ Francisco \\ Esteves $^{3}$ \\ 'Department of Audiology, Brito Mendes Otolaryngology Clinic, \\ Portugal \\ ${ }^{2}$ Instituto Universitário de Lisboa (ISCTE-IUL), CIS-IUL, Portugal \\ ${ }^{3}$ Department of Psychology, Mid Sweden University, Sweden
}

Correspondence: Joana D Alexandre, Instituto Universitário de Lisboa (ISCTE-IUL), CIS-IUL, Lisboa, Portugal,

Email joana.alexandre@iscte.pt

Received: February 28, 2015 | Published: May 23, 2015
Abbreviations: WHO, world health organization; EAS, social support scale; DASS, anxiety depression and stress scale; SD, standard deviation

\section{Introduction}

The elderly population has increased worldwide and Portugal is the fourth most aged country in the European Union. ${ }^{1}$ Moreover, chronic diseases seem to be associated with aging and are a major factor responsible for the gap between the curves of mortality and morbidity and so between average life expectancy and quality of life. ${ }^{2}$

Among the many problems associated with aging, hearing loss is the most common sensory deficit that affects more than 250million people worldwide. ${ }^{3}$ According to the World Health Organization Report (2007) hearing loss is characterized by a change in hearing thresholds. The World Health Organization (2004) listed this disease as the tenth in the list of diseases with increased influence on the human life conditions in 47 out of the 52 European countries. In Portugal in particular, it is considered the fifth leading cause of suffering with aging. 4,5

What impact does this disease have in their patients? Research has found that people with hearing loss have a reduction in normal social activities, increased problems in their relationship with family or friends, greater emotional difficulties at work and also higher levels of anxiety, depression, interpersonal sensitivity and hostility. ${ }^{6-8}$ At the same time research has been showing that social support can have an important role has on health protection. ${ }^{9-11}$

The importance of social support for older people has acquired an increasing relevance in recent years. However, literature only concerns the role of social support in aged population or in situations where hearing loss is associated with a specific population, such as the role of social support in families with deaf children. ${ }^{12,13}$

Therefore, this study aims to contribute to the understanding of the impact that hearing loss seems to have in a sample of individuals with aging hearing loss in different degrees, not only in their daily and social activities but also in their general emotional state. Furthermore, efforts will be made to analyze the role of social support as a protective factor in negative emotional symptoms (e.g. anxiety, depression and stress). For some researchers, chronic disease is a major problem that medicine and health sciences face. ${ }^{14}$ Presbycusis is the type of hearing loss that occurs with aging and is characterized by a progressive deterioration of hearing sensitivity, located at the level of the inner ear in which the cells of sensory hearing are lost and is distributed in four levels: mild, moderate, severe and profound. ${ }^{15}$ This is associated with genetic factors and can also be influenced by environmental factors, such as noise, ototoxic, alcohol and diabetes. ${ }^{16}$ Despite the early onset of symptoms in hearing disorders, the mean age at which patients seek, for the first time, an intervention for this problem is around 70years old. However, the majority ( $65 \%$ ) of people with hearing loss are less than 65years old and almost half of them are under 55years of age. ${ }^{17}$

Anxiety is part of human experience and works as a warning sign that makes us be alert and prepares us to fight or flee from a situation hazard. Although there is a relationship between anxiety and depression, both are constituted as two different constructs. ${ }^{18}$ Thus, depression is understood as an emotional disorder that can be translated in a state of dejection and unhappiness, which could be transient or permanent. According to the World Federation for Mental Health (2012), depression affects about 350million people worldwide, and within the general population, about $10 \%$ to $25 \%$ of 
people develop an episode of depression significant at some time in their life..$^{19}$

Hearing loss appears to negatively affect communication between family members, health professionals and others, which may lead to social isolation and subsequent symptoms of depression. ${ }^{20}$ The Better Hearing Institute (2012) found that people over the age of 50years, with hearing loss, not rehabilitated, were more likely to report depression, anxiety, anger, frustration, emotional instability and paranoia, and were less likely to participate in organized social activities than those that were rehabilitated. Also Bernabei et al., ${ }^{21}$ found that there is a significant association between hearing loss and depression in individuals aged 61 to $75 y$ ears. In the same study, individuals with hearing loss were more likely to develop anxiety when compared to participants with normal hearing. The results suggest that hearing loss with age can increase the likelihood of developing depressive symptoms and anxiety.

According to the human nature, all human beings have the desire to be inserted in particular social means, at home, at work or a group of friends. Therefore, individuals who share these contexts are also providers of social support. It is at home with the family, that the relationship with people establishes the primary relationships which constitute the support for later daily difficulties. ${ }^{22}$ All people face stress situations at some point in their lives. In particular there are many negative health effects that are caused by high stress levels and throughout time studies have been trying to find the best way to deal with it. Thus, psychologists have done extensive research on "how to deal with stress", and found that the one of best ways is to receive or to search social support. ${ }^{23}$

The idea that social support has effects on health protection is well empirically supported. ${ }^{24}$ Kessler et al., ${ }^{25}$ for example, in a research review concluded that social support can protect individuals at risk of subsequent mental disorders. In a study consisting of a sample of 369 patients with cancer, also Ell et al. ${ }^{26}$ concluded that there is a relationship evidence social relations and people survival with cancer. Gallant ${ }^{14}$ in a literature review about the relation between social support and chronic disease (especially diabetes, but also asthma, heart disease and epilepsy), provided evidence of a positive relationship between social support and self-management. ${ }^{25,26}$ Also Singer et al., ${ }^{27}$ conclude that social support acts as a protector factor for stress-induced disorders. In the same vein, social support appears to have a key role in mental health. Epidemiological studies show that negative life events which generate chronic stress such as financial problems, personal problems and threats to personal security affect the individual well-being and are associated with depression. ${ }^{10}$ However, social and environmental factors can modify the stressor effect on individuals, and the presence of social support may enable these people to cope better with environmental stressors. ${ }^{19}$ In fact, social support may moderate the stress effects on a psychological level which suggests that its presence gives the individual support, guidance and assistance. ${ }^{28}$

The purpose of the present study is to evaluate how the hearing loss limits daily and social activities as well as the emotional state. Although there is evidence of the protective role of social support in some chronically diseases, it is important to assess how much this variable moderates the relationship between hearing loss and negative emotional symptoms (anxiety, depression and stress).

Overall it is expected that the hearing loss will influence negatively the daily and social life activities and general emotional state of people with this pathology.

\section{Methods}

The sample consists of 110 adults diagnosed with hearing loss of which 18 have mild hearing loss degree, 59 have moderate hearing loss degree and 33 have severe hearing loss degree. This diagnosis was made by Pure Tone Audiometry which consists of a hearing threshold evaluation. Participants are aged between 55 and 85 years old $(M=70.01, S D=7.89)$ and of both sexes $(54.5 \%$ women and $45.5 \%$ men). Participants reside in metropolitan Lisbon area and are followed in a clinical or hospital context due to their hearing loss alone and no other disease.

The sample was collected in clinical and hospital. Participants were given an informed consent, ensuring anonymity and data confidentiality, in accordance with the ethical standards of the Declaration of Helsinki. After the consent agreement participant filled in the questionnaires. The application took on average 30minutes. After collection, data were introduced into SPSS database (Statistical Package Social Sciences, version 20.0) for statistical analysis.

The following instruments were applied: a socio-demographic questionnaire; a Social Support Scale (EAS, Matos et al., ${ }^{29}$ and the Portuguese adaptation (EADS-21, Pais-Ribeiro et al., ${ }^{18}$ of the Anxiety, Depression and Stress Scale (DASS-21, Lovibond et al. ${ }^{30}$ In the socio-demographic questionnaire, questions included allowed us to obtain information on age, sex, marital status, household situation, professional and academic qualifications. Apart from this characterization, aspects were questioned related to the participant's general health status and how their hearing loss affects different daily activities (e.g., "Your hearing impairment limits your social activities?" For these last two questions we used a Likert type scale $1-5$ where " 1 " is "Nothing" and " 5 " is "Totally". ${ }^{18,29,30}$

The Social Support Scale (EAS) was developed by the authors in order to contribute to the research on perceived social support in the Portuguese reality. ${ }^{29}$ It is a self-report scale that allows to understand how the individual evaluates his social support and more specifically in three dimensions: the information support (e.g., "I have people I can count on, in case of illness or other emergency"), emotional support (e.g., "I have no one to show as I am really.") and the instrumental support (e.g., "When I have enough money to meet my basic needs, know who to turn"). EAS includes a set of 16 questions used with a range type Likert five point's scale, corresponding " 1 " to low social support levels and the "5" to high social support levels.

The study of the internal consistency of this scale revealed that Cronbach's Alpha value is greater than 0.8 , indicating a good scale's reliability and in general, good psychometric characteristics. ${ }^{29}$ In the present study, the dimensions of instrumental support and information support obtained values of .66 and .77 respectively, and are therefore suitable. However, emotional support had a low Cronbach's $\alpha$ value of .43. Therefore, this dimension was not used for statistical analysis. For the analysis the former dimensions were transformed into a dichotomous variable: lower support (instrumental support and informational support) and higher support (instrumental support and informative support). The median was used for the dichotomization $(M d=2.1$ for instrumental support and $M d=2.8$ for informative support).

\section{Anxiety scale depression and stress (DASS-2 I)}

The Depression Anxiety and Stress Scale have 21 items distributed by three dimensions: Depression (e.g., "I was not able to have enthusiasm for anything"), Anxiety (e.g., "I felt scared without having 
a good reason for it") and Stress (e.g., "I felt I was using a lot of nervous energy"). ${ }^{18}$ Each item is a statement which refers to negative emotional symptoms. The participant has to answer if the statement applied to him "in the last week". Answers were given in a four points likert scale varying from 0 ("it does not apply to me") to 3 ("applied to me most of the time").

The internal consistency was considered good in the Portuguese version, with Alpha Cronbach values of .85 for depression, .74 for anxiety and .81 for the stress (EADS-21). ${ }^{31}$ In the present study all dimensions obtained good Cronbach's alpha values (.88 for anxiety, .87 for depression and .90 for stress). For statistical analysis purposes, three indexes were calculated corresponding to the three negative emotional symptoms analyzed.

\section{Results}

Results will be presented following the aims of the study described previously.

To test the extent to which hearing loss limits daily activities, social activities and also the general emotional state of individuals with this condition, an analysis of variance (ANOVA) was performed, in which level of hearing loss (mild, moderate or severe) was introduced as the independent variable and daily activities, social activities and general emotional state were the three dependent variables. This results showed that the hearing loss has a statistically significant effect on the three variables under study: daily activities $\mathrm{F}(2,109)=$ $25.23, \mathrm{p}<.001$, social activities $\mathrm{F}(2,109)=15.14, \mathrm{p}<.01$, and general emotional state, $\mathrm{F}(2,109)=11.18, \mathrm{p}=.01$.

Taking into account the three levels of the independent variable - mild degree, moderate degree and severe degree, through multiple comparison test (Bonferroni test), it was found that participants with a moderate and severe loss are the ones that reported greater limitations in their daily activities when compared with the group with mild loss. For social activities, there were differences between all degrees of hearing loss, namely, the higher the degree, the more complaints that their loss interferes significantly in their social activities, and therefore people who had a severe loss were those who reported more limitations in their social activities. On the other hand, regarding the emotional state, there were no differences between the two lower levels of hearing loss, but both reported lower levels of distress compared with people that have a severe loss degree (Table 1).

Table I Average difficulties in daily activities, social activities and general emotional state, depending on the hearing loss degree (mild, moderate and severe)

\begin{tabular}{llll}
\hline & $\begin{array}{l}\text { Hearing Loss } \\
\text { Degree }\end{array}$ & M & SD \\
\hline Daily Activities & Mild & 1,56 & 0,86 \\
& Moderate & 2,78 & 0,90 \\
& Severe & 3,30 & 0,77 \\
Social Activities & Mild & 1,83 & 1,04 \\
& Moderate & 2,66 & 0,84 \\
General Emotional State & Severe & 3,30 & 0,88 \\
& Mild & 2,11 & 1,13 \\
& Moderate & 2,69 & 1,04 \\
& Severe & 3,52 & 0,87 \\
\hline
\end{tabular}

In order to test how the perceived social support moderates the relationship between hearing loss and negative emotional symptoms (e.g., anxiety, depression and stress), separate $3 \times 2$ (mild, moderate or severe hearing loss $\mathrm{X}$ high or low support) ANOVAs were performed, both for Instrumental Support and for the Informative Support. Dependent variables were the three negative emotional symptoms: Anxiety, Depression and Stress. The analysis showed no significant effect of the degree of hearing loss on the dependent variables $(p>0.10)$. However, there was a statistically significant effect of instrumental support for all dependent variables: anxiety $F$ $(1,109)=17.1, \mathrm{p}<.01$ depression $F(1,109)=25.3, \mathrm{p}<.01$ and stress $\mathrm{F}(1,109)=16.5, \mathrm{p}<.01$. This means that individuals with a low instrumental support have higher anxiety symptoms $(\mathrm{M}=9.87, S D=$ $6.23)$, depression $(M=9.80, S D=5.73)$ and stress $(M=12.05, S D=$ 5.79), compared to individuals who sense higher instrumental support (Manxiety $=5.98, S D=3.88 ;$ Mdepression $=4.96, S D=3.49 ;$ Mstress $=7.73, S D=4.26$ ). There is also a trend to a significant interaction between hearing loss degree and instrumental support, but only in anxiety $F(2,109)=2.69, \mathrm{p}=.072$. Interestingly, as it can be seen in Figure 1, it is especially in patients with mild and severe hearing loss that the impact of the social support is felt, and not so much in the intermediate group.

Regarding the informative support, the analysis showed only a marginally significant result main effect of the social support in depression, $F(1,109)=3.75, \mathrm{p}=.056$ (Figure 2). Individuals with greater support tend to have a lower score in their depressive symptoms $(M=6.00, S D=5.06)$ when compared with the ones with less informative support $(M=8.71, S D=5.25)$.

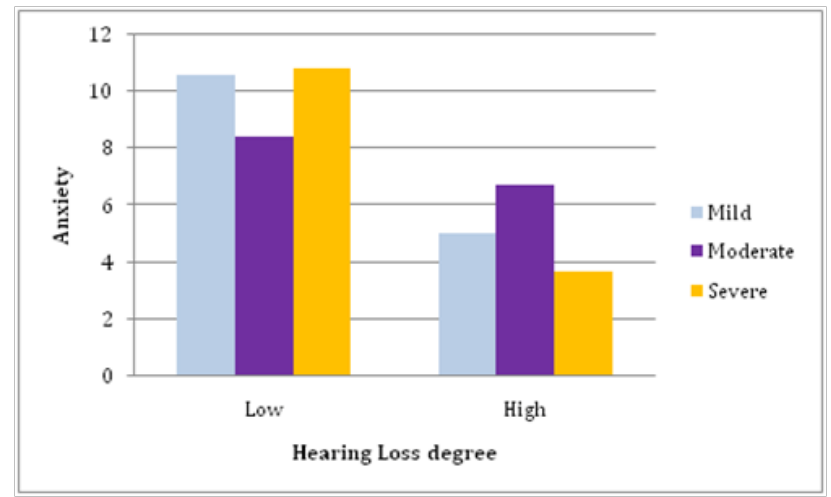

Figure I Anxiety level as a function of Hearing Loss degree (mild, moderate or severe) and perceived Instrumental Support level (low or high).

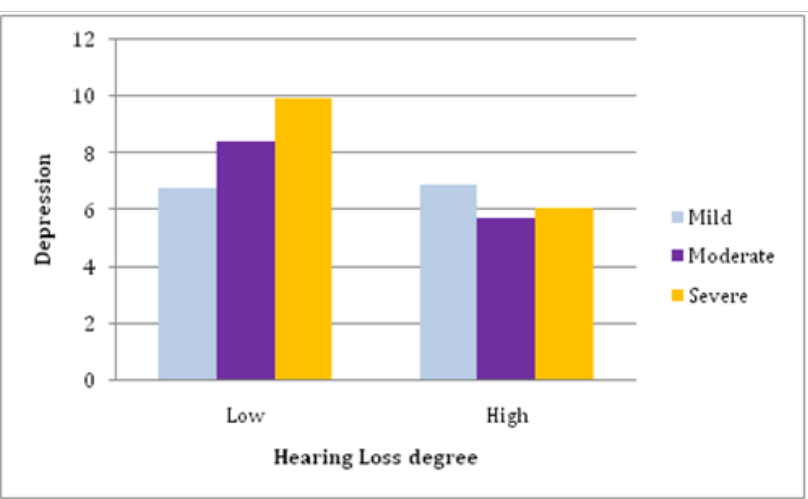

Figure 2 Depression level as a function of Hearing Loss degree (mild, moderate or severe) and perceived Informative Support level (low or high).

\section{Discussion}

This current study had two main goals: 1) to analyze the psychosocial impact (daily activities, social activities, general 
emotional state) of hearing loss; and 2) to verify to what extent the perceived social support moderates the relationship between hearing loss and negative emotional symptoms (anxiety, depression and stress).

The purpose of this study was also to contribute to this research this field with an attempt to discriminate the different levels of hearing loss degree since in most of the literature and studies were carried out taking into account hearing loss in general, ${ }^{6}$ without considering its severity level or, when evaluating the degree, they only considered the rehabilitated or not rehabilitated population. ${ }^{32}$ Furthermore, although the social support is a widely studied variable in health and chronic diseases and in the aging area, ${ }^{33,34}$ this research sought to study the social support role in a specific chronic disease - hearing loss with aging - for which yet there are no published studies that relate these two variables. In the literature, the only thing that was found relating this two variables directly were some studies on the social support assistance to the families of children with hearing loss. ${ }^{35}$

Considering the first goal, it was expected that the loss influenced negatively the daily and social life activities and general emotional state of people with this pathology, which turned out to be true, being this impact stronger on individuals with greater loss. These results are consistent with those of Ciorba and colleagues (2012) who found that hearing loss affects people on an emotional and social level. ${ }^{16}$

In what regards the second goal, it was expected that negative symptoms (anxiety, depression and stress) varied depending on hearing loss, with social support acting as a moderator in this relationship. In general, what we found was that the social support - and especially the instrumental support, which refers to the help that others can offer through favors, e.g., "I have nobody who can ask for small favors and offers" is a key variable in the report of negative emotional symptoms., In other words, the social support seems to be an important protective factor for the emergence of anxiety, depression and stress symptoms.

However it should be noticed that in the case of our study this comparison was only possible between instrumental support and informational support, as the emotional component had unsatisfactory reliability as was not considered.

Assumption is made that there is a significant effect of hearing loss in emotional negative symptoms and we found in the literature studies that point to this trend, although our results are in agreement with studies of Ciorba et al. ${ }^{16}$ which concluded that the diagnosis of hearing loss, by itself is not a significant risk factor to the anxiety and depression onset but there may be other variables, such as tinnitus and dizziness which present an influence in this symptoms. Supporting these results, authors Paulino et al., ${ }^{19}$ related to vertigo (labyrinthine symptom located at the inner ear level) and psychological disorders since the labyrinthine symptoms can lead to depression, in many cases, particularly with vertigo.

On the other hand, the Tanaka, Araujo, and Assencio et al., ${ }^{36}$ studies verified that the onset of depression and other mental health problems arise with increase in hearing loss degree. Taking into account the fact that our sample didn't include people with profound hearing loss degree, it may explain why hearing loss does not present a significant effect on these types of symptoms. All social support kinds present in community appear as a social relationship product which is present in times of difficulty. Analyzing Gallant, ${ }^{14}$ this is observed in chronic diseases cases such as diabetes and it might also be a part of this variable in other chronic diseases, in particular hearing loss. Dalgard et al. ${ }^{37}$ also verified that social support protects against the mental disorder development and, in their studies, it is especially protective for depression. Likewise the lack of social support will result in complications in terms of mental health but it is possible to avoid them. According to Chen, ${ }^{8}$ when problems associated with hearing loss are understood and new strategies are learned this leads to an improved self-perception quality of life. That said it is possible that hearing loss would inevitably affect people at their daily activities, social activities and general emotional state. However, according to the literature available and our results, these individuals fail to develop anxiety, depression and stress clinical symptoms if they have a good social support.

\section{Conclusion}

This study contributes to strengthening the argument that access to a greater social support throughout life is a powerful predictor to a happy aging with quality even with other disease situations that are not possible to avoid. Anxiety, depression and stress are not necessarily integrated in the morbidity of people with hearing loss. It is important in the planning of public health policies and chronic disease impact to promote awareness-raising actions, specifically in occupational, parental and educational universes for its effectiveness to be maximal on prevention. On the other hand, development of a health policy that promotes awareness-raising, as well as the maintenance of the current means of access to the existing social support, especially on what concerns the instrumental support, will certainly allow a better scarce of economic resources available for years to come, always keeping in mind the main goal of increasing of the perception of social support from individuals in the society.

Considering all the previously stated, in future investigations it is suggested to also investigate the quality of life of individuals, since some studies have already shown the relation that this variable seems to have with social support ${ }^{38}$ and also to use a sample that includes individuals with a profound degree of hearing loss, since it is a more pronounced change, and as such may have an impact on the level of emotional negative symptoms in these individuals. In the near future, it will be necessary to improve our understanding of this disease and its pathophysiology in an attempt to minimize its progression. Furthermore, it is of great importance to improve methods of identifying individuals with presbycusis, improving the supply of hearing rehabilitation services and learning coping strategies that can have a positive impact on life quality of individuals with hearing loss.

\section{Acknowledgments}

None.

\section{Conflicts of interest}

Author declares there are no conflicts of interest.

\section{Funding}

None.

\section{References}

1. Campos A. Portugal é o quarto país mais envelhecido da União Europeia. Público ID. 2013.49097196.

2. Hanson BS, Isacsson SO, Janzon L, et al.Social network and social support influence mortality in elderly men. The prospective population study of "Men born in 1914," Malmo, Sweden. Am J Epidemiol. 1989;130(1):100-111.

3. Mathers C, Smith A, Concha M. Global burden of hearing loss in the year 2000. World Health Organization technical report series, Geneva, Switzerland. 2000. p. 1-30. 
4. World Health Organization (WHO) . Guidelines for hearing aids and services for developing countries. ( $2^{\text {nd }}$ edn), World Health Organization technical report series, Geneva, Switzerland; 2004.

5. Harkin H, Kelleher C. Caring for older adults with hearing loss. Nurs Older People. 2011;23(9):22-28.

6. Baraldi GS, Almeida LC, Borges AC. Hearing loss in aging. Braz J Otorhinolaryngol . 2007;73(1):64-70.

7. Better Hearing Institute. Hearing Healthcare Professionals. Obtido de Better Hearing, Institute. 2012.

8. Chen A, Most T. Auditory, Visual, and Auditory-Visual Perception of Emotions by Individuals With Cochlear Implants, Hearing Aids, and Normal Hearing. J Deaf Stud Deaf Educ. 2009;14(4):449-464.

9. Dimond M. Social support and adaptation to chronic illness: The case of maintenance hemodialysis. Res Nurs Health. 2007;2(3):101-108.

10. Ribeiro JL. Escala de Satisfação com o Suporte (ESSS). Análise Psicológica. 1999;3(XVII):547-558.

11. Silva I, Pais-Ribeiro J, Cardoso H, et al. Efeitos do apoio social na qualidade de vida, controlo metabólico e desenvolvimento de complicações crónicas em indivíduos com diabetes. Psicologia, Saúde \& Doenças. 2003;4(1):21-32.

12. Schwarzer R, Leppin A. Social support and health: A theoretical and empirical overview. Journal of Social and Personal Relationships. 1991;8:99-127.

13. Van Gent T, GoedhartAW, Treffers PD. Self-concept and psychopathology in deaf adolescents: preliminary support for moderating effects of deafness-related characteristics and peer problems. J Child Psychol Psychiatry. 2011;52(6):720-728.

14. Gallant MP. The influence of social support on chronic illness selfmanagement: a review and directions for research. Health Educ Behav. 2003;30(2):170-195.

15. Most T, Michaelis H. Auditory, Visual, and Auditory--Visual Perceptions of Emotions by Young Children With Hearing Loss Versus Children With Normal Hearing. J Speech Lang Hear Res. 2012;55(4):1148-1162.

16. Ciorba A, Bianchini C, Pelucchi S, et al. The impact of hearing loss on the quality of life of elderly adults. Clin Interv Aging. 2012;7:159-163.

17. Kochkin S. The Impact of Treated Hearing Loss on Quality of Life Obtido de Better Hearing Institute. 2011.

18. Pais-Ribeiro J, Honrado A, Lea I . Contribuição para o estudo da adaptação portuguesa das escalas de ansiedade, depressão e stress (EADS) de 21 itens de Lovibond e Lovibond. Psicologia, Sáude \& Doenças. 2004;5(2):229-239.

19. Paulino CA, Prezotto AO, Calixto RF. Association between stress, depression and dizziness: a brief review. Revista Equilíbrio Corporal e Saúde. 2009;1:33-45.

20. Linssen AM, Joore MA, Theunissen EJ, et al. The Effects and Costs of a Hearing Screening and Rehabilitation Program in Residential Care Homes for the elderly in the Netherlands1. Am J Audiol. 2013;22(1):186-189.

21. Bernabei V, Morini V, Moretti F, et al. Vision and hearing impairments are associated with depressive-anxiety syndrome in Italian elderly. Aging Ment Health. 2011;15(4):467-474.
22. Leite MT, Battisti ID, Berlezi EM, et al. Elderly urban residents and their family and social support networks red de apoyo familiar y social de ancianos residentes en el medio urbano. Texto Contexto Enferm. 2008;17(2):250-257.

23. Baqutayan S. Stress and social support. Indian J Psychol Med. 2011;33(1):29-34.

24. Lino VT, Portela MC, Camacho LA, et al. Assessment of Social Support and Its Association to Depression, Self-Perceived Health and Chronic Diseases in Elderly Individuals Residing in an Area of Poverty and in Elderly Individuals Residing in an Area of Poverty and Social Vulnerability in Rio de Janeiro city, Brazil. PLoS One. 2013;8(8):e71712.

25. Kessler RC, McLeod JD. Social support and mental health in community samples. In: Cohen S \& Leonard SS (Eds.), Social support and health. 1985. p. 219-240.

26. Ell K, Nishimoto R, Mediansky L, et al.Social relations, social support and survival among patients with cancer. J Psychosom Res. 1992;36(6):531-541.

27. Singer JE, Lord D. The role of social support in coping with chronic or life-threatning illness. In: Baum A, Taylor S, Singer J (Eds.), Handbook of psychology and health (Vol. IV, pp. 269-278). New Jersey: Laurence Erlbaum Associates, Inc., Publishers. 1984.

28. Sandier IN, Lakey B. Locus of Control as a Stress Moderator: The Role of Control Perceptions and Social Support. Am J Community Psychol. 1982;10(1):65-80.

29. Matos A, Ferreira A. Desenvolvimento duma Escala de Apoio Social: alguns dados sobre a sua fiabilidade. Psiquiatria Clínica. 2000. p. 243-253.

30. Lovibond PF, Lovibond SH. The structure of negative emotional states: comparison of the Depression Anxiety Stress Scales (DASS) with the Beck Depression and Anxiety Inventories. Behav Res Ther. 1995;33(3):335-343.

31. Marôco J. Análise Estatística com utilização de SPSS. Lisboa. Edições Silabo. 2007.

32. Hundertmarck AL, Julio Costa JM, Becker KT. Satisfaction of Hearing Aids Users With Hearing Loss of Severe and Deep Degree. Arq Int Otorrinolaringol. 2010;14(3):338-345.

33. Paúl C. Envelhecimento activo e redes de suporte social. Sociologia: revista da Faculdade de Letras do Porto. 2005;275-288.

34. Paúl C, Fonseca A. Psicossociologa da saúde. Lisboa: Climepsi Editores. 2001.

35. Alvarenga MR, Oliveira MA, Domingues MA, et al. Social support networks for elderly patients attended by Family Health teams. Cien Saude Colet. 2011;16(5):2603-2611.

36. Tanaka M, Araújo V, Assencio-Ferreira V. Hearing loss in elderly could difficult the communication? CEFAc. 2002. p. 203-205.

37. Dalgard OS, Bjork S, Tambs K. Social support, negative life events and mental health. Br J Psychiatry. 1995;166(1): 29-34.

38. Carneiro RS, Falcone E, Clark C, et al. Quality of Life, Social Support and Depression of the Elderly: Relation with Social Abilities. Psicologia: Reflexão e Crítica. 2007;20(2):229-237. 